\title{
Leptin and interleukin-6 level in patients with hypertension and obesity combined with non-alcoholic steatohepatitis during treatment with sartans and statins
}

\author{
Olesya Bochar $^{1 \star}$, Eugene Sklyarov ${ }^{1}$, Volodymyr Bochar ${ }^{2}$ \\ ${ }^{1}$ Postgraduate Department №1 Therapy and Medical Diagnostics Danylo Halytsky Lviv National Medical University, Ukraine \\ ${ }^{2}$ Postgraduate Department of surgery and endoscopy Danylo Halytsky Lviv National Medical University, Ukraine
}

\section{ARTICLE INFO \\ Received 14 February 2017 Accepted 24 May 2017}

\section{Keywords:}

arterial hypertension, obesity,

non-alcoholic steatohepatitis, olmesartan,

telmisartan, atorvastatin.

\begin{abstract}
The results of treatment of patients with arterial hypertension and obesity combined with non-alcoholic steatohepatitis are presented in article. Herein, the combined use of olmesartan or telmisartan with atorvastatin for 12 weeks had a positive impact on the physical condition of patients with arterial hypertension and obesity. This effect was manifested by maintenance of optimal blood pressure, the reduction of subjective complaints and the improvement of heart hemodynamics. Administration of sartans and statins to patients with arterial hypertension combined with obesity and non-alcoholic steatohepatitis led to a significant reduction of LDL $(\mathrm{p}<0.01)$ and LDL cholesterol levels $(\mathrm{p}<0.01)$, as well as the values of leptin $(\mathrm{p}<0.01)$ and IL-6 $(\mathrm{p}<0.01)$. The combination of olmesartan or telmisartan with atorvastatin not only allows a control of BP, but also a reduction of the pro-atherogenic fractions of blood lipids, hyperleptinaemia and levels of pro-inflammatory IL-6, hence, in this manner, improving the patient general condition.
\end{abstract}

\section{INTRODUCTION}

In Ukraine, cardiovascular disease (CVD) accounts for $62,5-63,4 \%$ of total mortality. In particular, at least $75-80 \%$ of all deaths from cardiovascular disease are associated with atherosclerotic lesions of vessels, namely arterial hypertension $(\mathrm{AH})$, heart attack and stroke $[1,5,6,8,14]$.

Against a background of obesity, the treatment of AH needs serious monitoring of blood pressure and the prevention of complications. Modern recommendations for the treatment of AH include primary prescription of anti-hypertensive agents - direct renin inhibitors (kirens), ACE inhibitors, beta-blockers, calcium antagonists, long-acting diuretics, as well as angiotensin-II receptor antagonists (sartans), etc. However, there are no reasonable recommendations for the treatment of comorbid conditions - hypertension, obesity and NAFLD.

Nowadays, in the treatment of patients with AH, angiotensin-II receptor antagonists (sartans) play a leading role. These block the effects of the angiotensin-II and reninangiotensin-aldosterone system (RAAS) activity during the day, as well as have a better tolerability profile and do not cause dry cough $[2,12]$. There is major evidence for

\footnotetext{
* Corresponding author

e-mail: olesjabarduw@ukr.net
}

the effectiveness of sartans in reducing the risk of serious (even fatal) cardiovascular AH complications [4]. Indeed, in clinical trials and medical practice, small doses (10 and $20 \mathrm{mg}$ ) of sartans had demonstrated the ability to provide a pronounced and stable reduction of SBP and DBP in patients with mild to moderate $\mathrm{AH}[4,11]$.

Among the angiotensin-II receptor antagonists, beside the anti-hypertensive properties, the additional effects of olmesartan and telmisartan administration should be noted. These demonstrate varying selectivity for the AT1 receptors of angiotensin-II and show possible influence on the stages of systemic inflammation [3].

According to TRANSCEND and ONTARGET studies, sartans help to restore the endothelial function of blood vessels by generating an increase of nitric oxide production and enhancing the sensitivity of tissues to insulin. Moreover, some affect the concentration of adiponectin in the blood plasma of obese patients $[7,9,15,16]$.

The additional effects of angiotensin-II receptor antagonists are due to the chemical structure and nature of the interaction with these receptors. Among the pharmacologically active substances, telmisartan has a stronger ability to act as a partial agonist of peroxisomes of proliferation activator receptor gamma (PPAR- $\gamma$ ) than other drugs in the sartan 
group, and within prolonged therapy, reduces the myocardial mass index of the left heart ventricle [7,13].

On the other hand, olmesartan has a special mechanism for binding to AT1 receptors to angiotensin-II, providing prolonged blockade for 24 hours. According to EUTOPIA and ESPORT studies, olmesartan in small doses (20 mg/day), reduces the levels of CRP and tumor-necrosis factor and effectively influences the inflammatory markers (interleukin-6) [3].

However, there are some difficulties in the treatment of AH combined with obesity and non-alcoholic steatohepatitis. These come about due to the necessity to take into account the level of leptin, the level of liver enzymes and the blood lipid spectrum.

Excessive accumulation of abdominal fat, which produces the leptin, is usually accompanied by metabolic disorders, and it increases the risk of hypertension, atherosclerotic diseases and type 2 diabetes [10]. Among the population of the USA, the increase of levels of leptin is specifically associated with myocardial infarction and stroke, both in men and women, regardless of traditional cardiovascular risk factors [10]. It should also be taken into consideration that immunoinflammatory processes with increased levels of pro-inflammatory cytokines, including IL-6, play a significant role in the remodeling of the cardiovascular system.

\section{AIM}

The aim of the work was to evaluate the dynamics of leptin, IL-6 and blood lipid spectrum, as well as liver enzymes in patients with $\mathrm{AH}$ accompanied with obesity and non-alcoholic steatohepatitis, during the prescription of olmesartan or telmisartan combined with atorvastatin.

\section{MATERIALS AND METHODS}

The study involved 50 patients with stage II-III AH who were hospitalized in an elective manner. After an initial examination, the patients were placed into 2 groups and the therapy was prescribed: olmesartan or telmisartan combined with atorvastatin for the next 12 weeks. Among the patients who passed clinical and diagnostic examination, 28 (56\%) were women and 22 (44\%) were men. The mean age of the test population was $58.2 \pm 0.97$.

Diagnosis of $\mathrm{AH}$ was put according to the standards of diagnosis and treatment of this disease, and was in accordance with the recommendations of the Ukrainian Association of Cardiology (2012), the European Society of Hypertension and the European Society of Cardiology (ESH/ESC, 2013). What is more, while choosing the treatment strategy and plan of survey, we referred to the «Order of $\mathrm{MOH}$ of Ukraine from 24.05.2012 No. 384 «On approval and introduction of medical and technological documents for the standardization of medical care of arterial hypertension».

All patients underwent anthropometric, general clinical, laboratory (blood lipid profile, liver transaminases) and instrumental methods (electrocardiography, echocardiography, ultrasonography, metacetin 13C-breath test, ELISA (leptin, IL-6). The patients were also measured for height and weight, and body mass index was calculated according to common formulas.

The level of office blood pressure (BP) was measured in the morning in a sitting position, on the same arm, at intervals of $2 \mathrm{~min}$, thrice; the average of 3 measurements was calculated. Heart rate (HR) was evaluated after the second measurement.

We determined the levels of total cholesterol (TC), cholesterol of high-density lipoprotein (HDL), cholesterol of low density lipoprotein (LDL), triglycerides (TG), activities of aspartate aminotransferase (AST) and alanine aminotransferase (ALT) in serum, and the level of leptin, IL-6 by ELISA immunoassay.

To identify the ultrasonographic signs of non-alcoholic steatohepatitis, all individuals passed ultrasonography (USG) of internal organs, with particular attention paid to increase of liver size, the density of its parenchyma, diffuse homogenous increase of echogenicity, appearance of distal shadowing and increase of diameter of portal vein. Fatty liver was determined in case of increase of liver size, diffuse homogeneous echogenicity and the appearance of distal shadowing.

These patients then orally received metacetin which was tagged with radioactive carbon isotope $13 \mathrm{Cm}$, to determine the functional state of their microsomal enzyme systems of hepatocytes via the metacetin 13C-breath test. Analysis of air samples conducted using infrared spectrometer IRIS ("Wagner", Germany).

The metabolic efficacy of drugs was assessed by the dynamics of the lipid profile, liver enzymes, leptin, IL-6 and hemodynamic parameters. After the initial examination, patients of group 1 were prescribed telmisartan $20 \mathrm{mg}$ and atorvastatin $20 \mathrm{mg}$ once a day, while patients of group 2 were administered olmesartan $10 \mathrm{mg}$ and atorvastatin $20 \mathrm{mg}$ once a day. Clinical, hemodynamic and laboratory efficacy of these drugs were evaluated after 12 weeks of treatment. Therapy was considered effective if till the end of the observation period, the target BP was 130/85 mm Hg and below. Metabolic efficiency of treatment was evaluated by the dynamics of lipid profile, liver enzymes, leptin, IL-6 and hemodynamic parameters.

The results were processed statistically using Student's test and Pearson correlation analysis, by way of «Microsoft Excel» software.

\section{RESULTS AND DISCUSSION.}

During their clinical examination, patients expressed the following complaints: heaviness, pain in the forehead and occipital region, "flies before eyes", vertigo, tinnitus, irregular heartbeat, shortness of breath, cardiac discomfort, dizziness, palpitations, fatigue, nasal bleeding, general weakness and sleep disturbances.

In group 1,14 patients (56\%) had stage II AH, and 11 (44\%) had stage III. Average systolic blood pressure (SBP) was $154.34 \pm 1.62 \mathrm{~mm} \mathrm{Hg}$, while diastolic blood pressure (DBP) was $92.38 \pm 1.01 \mathrm{~mm} \mathrm{Hg}$. Heart rate was within $84.51 \pm 0.39$ per minute. In group 2, 13 patients (52\%) had stage II AH, and $12(48 \%)$ had stage III. Mean SBP levels 
were $160.23 \pm 2.97 \mathrm{~mm} \mathrm{Hg}$ and DBP $-94,77 \pm 0.96 \mathrm{~mm} \mathrm{Hg}$, respectively. Heart rate was $85.36 \pm 0.67$ per minute.

Burdened heredity in relation to the main disease was identified in $28(63.3 \%)$ patients.

Stage 1 obesity was found in 16 patients $(72.7 \%)$ of group 1 , and in 10 patients of group $2(45.5 \%)$. Stage 2 obesity was diagnosed in 6 patients $(27.3 \%)$ of group 1 , and in 12 patients $(54.5 \%)$ of group 2 .

According to the liver ultrasonography, hepatomegaly was seen in all patients, as was heterogeneous consolidation of parenchyma (hyperechogenicity, «damping» of signal), diffuse fatty infiltration and medium-grain structure transformation. The dimensions of the portal vein of group 1 patients were within $11.65 \pm 0.32$, while in group 2 , the dimensions were within $11.35 \pm 0.23$ (Table 2).

According to the metacetin 13C-breath test, the average metabolic rate was $13,61 \pm 0.62($ Dose $/ \mathrm{h} \%)$ in group 1 patients, and $13,70 \pm 0.48$ (Dose/h\%) in patients of group 2 , respectively. A decrease of cumulative dose after 40 and 120 minutes was also noted (Table 1).

Table 1. Results of the metacetin ${ }^{13} \mathrm{C}$-breath test

\begin{tabular}{|c|c|c|}
\hline Indexes & $\begin{array}{c}\text { I group (telmisartan } \\
\text { and atorvastatin) }\end{array}$ & $\begin{array}{c}\text { II group (olmesartan } \\
\text { and atorvastatin) }\end{array}$ \\
\hline Metabolic rate (Dose/h\%) & $13.61 \pm 0.62$ & $13.70 \pm 0.48$ \\
\hline CUM40 (\%) & $7.07 \pm 0.42$ & $7.39 \pm 0.32$ \\
\hline CUM120 (\%) & $13.0 \pm 0.97$ & $12.24 \pm 0.57$ \\
\hline
\end{tabular}

After 12 weeks of treatment with telmisartan or olmesartan combined with atorvastatin, in both groups, a significant improvement of general condition was seen. The latter observation was demonstrated by a reduction of all complaints, especially the pain in the forehead and occipital area, cardiac discomfort and palpitations.

The therapy was effective in 17 patients $(68 \%)$ of group 1 , and in 20 patients $(80 \%)$ of group 2 , and was found to be depended on their state. Beyond the aforementioned, we objectively observed the decline of hemodynamic parameters (SBP, DBP, HR) in patients of both groups (Tab. 2), which corresponds to the study of other authors [14].

Table 2. Levels of blood pressure, blood lipid spectrum and liver enzymes before and after treatment with telmisartan or olmesartan

\begin{tabular}{|c|c|c|c|c|c|c|}
\hline \multirow{2}{*}{ Indexes } & \multicolumn{3}{|c|}{$\begin{array}{l}\text { I group (telmisartan } \\
\text { and atorvastatin) }\end{array}$} & \multicolumn{3}{|c|}{$\begin{array}{c}\text { II group (olmesartan } \\
\text { and atorvastatin) }\end{array}$} \\
\hline & $\begin{array}{c}\text { To } \\
\text { treatment }\end{array}$ & $\begin{array}{c}\text { After } \\
\text { treatment }\end{array}$ & $\mathrm{p}$ & $\begin{array}{c}\text { To } \\
\text { treatment }\end{array}$ & $\begin{array}{c}\text { After } \\
\text { treatment }\end{array}$ & $\mathrm{p}$ \\
\hline SBP $\mathrm{mm} \mathrm{Hg}$ & $\begin{array}{c}154.34 \\
\pm 1.62\end{array}$ & $\begin{array}{l}141.20 \\
\pm 1.16\end{array}$ & $<0.01$ & $\begin{array}{c}160.23 \\
\pm 2.97\end{array}$ & $\begin{array}{c}146.07 \\
\pm 1.18\end{array}$ & $<0.01$ \\
\hline DBP $\mathrm{mm} \mathrm{Hg}$ & $\begin{array}{l}92.38 \\
\pm 1.01 \\
\end{array}$ & $\begin{array}{l}78.60 \\
\pm 0.61 \\
\end{array}$ & $<0.01$ & $\begin{array}{l}94.77 \\
\pm 0.96 \\
\end{array}$ & $\begin{array}{l}81.05 \\
\pm 0.34\end{array}$ & $<0.01$ \\
\hline TC & $\begin{array}{c}5.99 \\
\pm 0.19 \\
\end{array}$ & $\begin{array}{c}4.90 \\
\pm 0.22\end{array}$ & $<0.01$ & $\begin{array}{c}6.33 \\
\pm 0.21 \\
\end{array}$ & $\begin{array}{c}4.92 \\
\pm 0.17 \\
\end{array}$ & $<0.01$ \\
\hline HDL & $\begin{array}{c}1.23 \\
\pm 0.06\end{array}$ & $\begin{array}{c}1.21 \\
\pm 0.06\end{array}$ & $>0.05$ & $\begin{array}{c}1.29 \\
\pm 0.07\end{array}$ & $\begin{array}{c}1.14 \\
\pm 0.04\end{array}$ & $>0.05$ \\
\hline LDL & $\begin{array}{c}3.93 \\
\pm 0.19\end{array}$ & $\begin{array}{c}3.15 \\
\pm 0.19\end{array}$ & $<0.01$ & $\begin{array}{c}3.97 \\
\pm 0.20\end{array}$ & $\begin{array}{c}3.05 \\
\pm 0.13\end{array}$ & $<0.01$ \\
\hline TG & $\begin{array}{c}1.92 \\
\pm 0.12\end{array}$ & $\begin{array}{c}1.67 \\
\pm 0.12\end{array}$ & $>0.05$ & $\begin{array}{c}1.97 \\
\pm 0.13\end{array}$ & $\begin{array}{c}2.16 \\
\pm 0.15\end{array}$ & $>0.05$ \\
\hline leptin & $\begin{array}{l}49.10 \\
\pm 9.35\end{array}$ & $\begin{array}{l}37.49 \\
\pm 7.07\end{array}$ & $<0.01$ & $\begin{array}{l}34.60 \\
\pm 8.50\end{array}$ & $\begin{array}{l}27.64 \\
\pm 8.10 \\
\end{array}$ & $<0.01$ \\
\hline IL-6 & $\begin{array}{c}8.85 \\
\pm 1.09\end{array}$ & $\begin{array}{c}3.73 \\
\pm 0.57\end{array}$ & $<0.01$ & $\begin{array}{c}7.60 \\
\pm 1.10\end{array}$ & $\begin{array}{l}3.21 \\
\pm 0.44\end{array}$ & $<0.01$ \\
\hline ALT & $\begin{array}{c}0.67 \\
\pm 0.06\end{array}$ & $\begin{array}{c}0.50 \\
\pm 0.02\end{array}$ & $<0.01$ & $\begin{array}{c}0.70 \\
\pm 0.14\end{array}$ & $\begin{array}{c}0.47 \\
\pm 0.03\end{array}$ & $<0.01$ \\
\hline AST & $\begin{array}{c}0.53 \\
\pm 0.03\end{array}$ & $\begin{array}{c}0.45 \\
\pm 0.02\end{array}$ & $>0.05$ & $\begin{array}{c}0.50 \\
\pm 0.04\end{array}$ & $\begin{array}{c}0.44 \\
\pm 0.02\end{array}$ & $>0.05$ \\
\hline
\end{tabular}

The appointment of atorvastatin in the treatment of olmesartan or telmisartan was seen to lead to a significant reduction in general cholesterol levels $(\mathrm{p}<0.01)$ and particularly in LDL cholesterol levels $(p<0.05)$. At the same time, no significant differences had been observed between the values of TG and HDL cholesterol ( $p>0.05)$. Moreover, a likely reduction of ALT levels after the applied treatment against a background of normalization of AST levels was noted (Tab. 2).

A comparison of leptin and IL-6 levels showed a significant decrease in fat hormone levels and in pro-inflammatory cytokine as a result of treatment with olmesartan or telmisartan in combination with atorvastatin (Tab. 2).

Therefore, the 12-week combined therapy consisting of telmisartan or olmesartan with atorvastatin resulted in a significant improvement of patients' condition and a reduction of clinical signs of disease, alongside with stabilization of SBP, DBP, HR.

An important feature of these drugs is their ability not only to affect hemodynamic parameters and to reduce SBP and DBP, but also to reduce levels of leptin and pro-inflammatory IL-6. This effect improves the general condition of patients. Thus, in patients with $\mathrm{AH}$ combined with obesity and non-alcoholic steatohepatitis, angiotensin-II receptor antagonists with atorvastatin improve the hemodynamic parameters and contribute to a decrease of pro-atherogenic fractions of blood lipid spectrum and the levels of IL-6 and leptin. The research results, hence, have revealed the effectiveness of the anti-hypertensive effect of olmesartan or telmisartan in patients with AH combined with obesity and NASH. At the same time, it is noteworthy that in $32 \%$ of patients receiving telmisartan and in $20 \%$ receiving olmesartan, the anti-hypertensive effect was less pronounced, being probably associated with the severity of comorbid disorders.

\section{CONCLUSIONS}

1. The combined use of olmesartan or telmisartan with atorvastatin for 12 weeks had a positive impact on the physical condition of patients with $\mathrm{AH}$ and obesity. This effect was manifested by the maintenance of optimal BP, the reduction of subjective complaints, and the improvement of heart hemodynamics.

2. Administration of sartans and statins to patients with $\mathrm{AH}$ combined with obesity and non-alcoholic steatohepatitis has led to a significant reduction of LDL $(p<0.01)$ and LDL cholesterol levels $(p<0.01)$, as well as the values of leptin $(\mathrm{p}<0.01)$ and IL-6 $(\mathrm{p}<0.01)$.

3. The combination of olmesartan or telmisartan with atorvastatin not only allows medical personnel to control BP, but also to reduce the pro-atherogenic fractions of blood lipids, hyperleptinaemia and levels of pro-inflammatory IL-6, thus, in this manner, improving the general condition of their patients.

\section{REFERENCES}

1. Amosova E.N.: From the treatment of atherosclerosis by modifying the forecast: Focus on lipidlowering therapy. Chapter 1. Sertse i sudyny, 33, 6, 2011

2. Bablyak S.D. Khomyn A.M.: An experience of the use of combined antihypertensive therapy in aged women with long) lasting arterial hypertension. Medytsyna transportu Ukrainy, 2, 64, 2008. 
3. Boychak M.P.: Additional effects of angiotensin II receptor antagonists in the treatment of patients with hypertension. Therapia, 54, 37, 2011.

4. Egorov I.E.: Hypertension: the evolution of approaches to treatment Health of Ukraine, 2, 67, 2013.

5. Gerasimova A.S., Oleinikov V.E., Yeliseyeva I.V.: The peculiarities of arterial hypertension course and involvement of the target organs in metabolic syndrome. International Medical Journal, 3, 22, 2008

6. Gubergrits N.B. Lareva N.V.: Statins in hepatology: a "princess frog» or a "toad»? Contemporary gastroenterology [Suchasna gastroenterologia], 6, 78, 2011

7. Ikejima H. et al.: Effects of telmisartan, a unique angiotensin receptor blocker with selective prexisome proliferatoractivated receptor-gamma-modulating activity, on nitric oxide bioavaliability and atherosclerotic change. J. Hypertens, 26, 964, 2008.

8. Khukhlina O.S., Gorbatiuk I.B.: The investigation of rosuvastatin and mosaprid influence on the changes of the blood lipid profile, the level of insulin resistance and bilelithogenicity in patients with chronic stone-free cholecystitis, in combination with obesity and ischemic heart disease. Clin. and expirem. Pathol., 10, 143, 2011.

9. Kubik M. et al.: Telmisartan improves cardiometabolic profile in obese patients with arterial hypertension. Kidney Blood Press. Res., $35,281,2012$.
10. Mitchenko O.I. et al.: Leptin adiponectin index as a new additional surrogate marker of atherosclerotic lesions. Ukraiinskyj cardiologichnyj zhurnal, 2, 40, 2012.

11. Nakayama S. et al.: Comparison of effects of olmesartan and telmisartan on blood pressure and metabolic parameters in Japanese early-stage type-2 diabetics with hypertension. Hypertens Res., 31, 7, 2008.

12. Neutel J.M.: Choosing among reninangiotensin system blockers for the management of hypertension: from pharmacology to clinical efficacy. Current Medical Research \& Opinion, 26, 213, 2010.

13. Pérez-Castrillón J.L. et al.: Telmisartan effect's on remodelling bone markers in hypertensive patients. Nutr Hosp., 27, 276, 2012.

14. Solomenchyk T.M. et al.: Efficacy of Rosuvastatin in patients with hypertension of high cardiovascular risk. Liky Ukrainy, 9-10, 82, 2013.

15. The ONTARGET investigators. Telmisartan, ramipril or both in patients at high risk for vascular events. N Engl J Med., 358, 1547, 2008.

16. The TRANSCEND investigators. Effects of the angiotensinreceptor blocker telmisartan on cardiovascular events in high-risk patients intolerant to angiotensin-converting enzyme inhibitors: a randomised controlled trial. Lancet, 372, 1174, 2008. 